\title{
IMPLANTAÇÃO DE UM NOVO MODELO DE TREINAMENTO EM UM HOSPITAL ONCOLÓGICO - RELATO DE EXPERIÊNCIA
}

Ana Lígia Alcalde Mazziero Sylvia de Almeida Francisco Valdez Santos Paola A. de Oliveira Lucchesi Natasha De Lutiis Nedachi 


\section{Introdução e Objetivos}

QUALIHOSP 2019

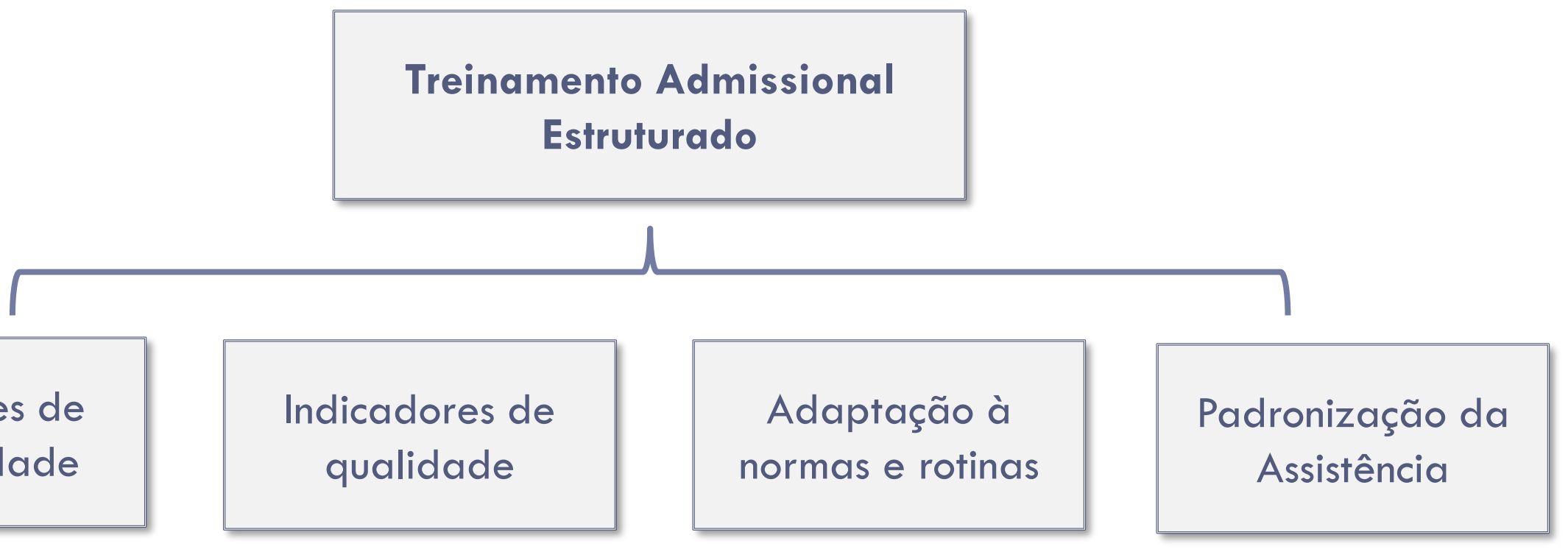

Indicadores de produtividade

\section{qualidade}

\section{Adaptação à} normas e rotinas
Padronização da

Assistência

Descrever modelo de treinamento admissional com imersão em ambiente simulado de assistência de enfermagem ao paciente oncológico em hospital de referência no atendimento oncológico 


\section{Método}

Linha de cuidados

em oncologia

- Foco nas

(1) necessidades do paciente e família

Aplicabilidade prática de conhecimento técnico
O profissional recém admitido é agente ativo e responsável pela sua aprendizagem

Desenvolver o comprometimento com o aprendizado profissional
Seis dias consecutivos de internação de um paciente oncológico

- simulando situações desde sua admissão

$?$ até o desfecho

clínico no último dia de treinamento.

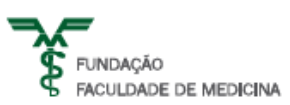




\section{Método}

D6 - Cuidados ao paciente em Cuidados Paliativos em fase final de vida

- Cuidados Paliativos e sedação paliativa

- Punção e manejo de Hipodermóclise

- Cuidados com óbito D4 - Cuidados ao paciente oncológico em situação de Urgência e Emergência Organização do Time de Resposta Rápida Emergências Oncológicas Análise de casos clínicos

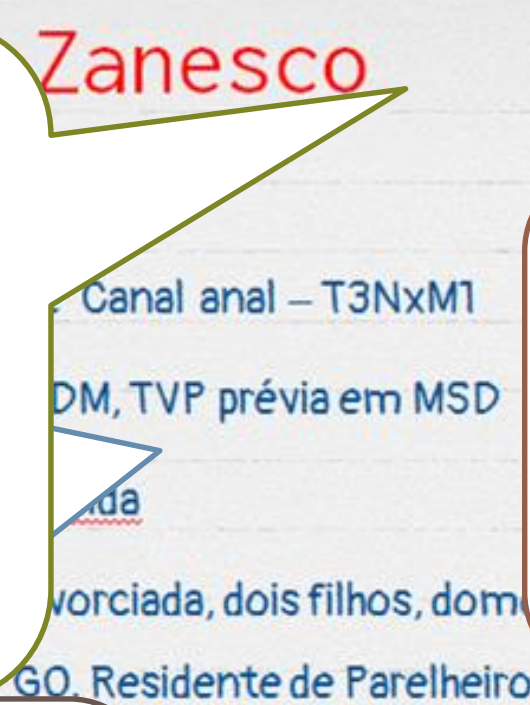

\section{6o}

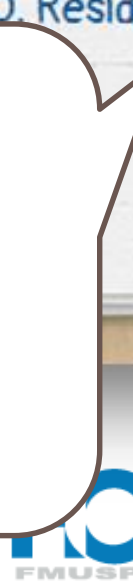

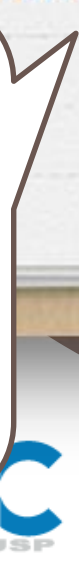

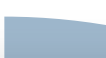

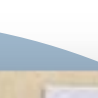

\section{D3 - Tratan} cuidados ao operatório de cir..

- Cuidados com drey

- Cuidad

c Eratórias 1

D2 - Processos de segurança

- Administração de medicamentos

- Avaliação da dor - Manejo de pacientes com risco de queda as de 1 atra-hospitalar para tratamento oncológico

- Bases da oncologia

- Exame físico e admissão Cuidados com paciente (pacinete) em quimioterapia

- Terapia intravenosa e manejo de chatplet/prereessings.science/p/112407?lang=pt-br 


\section{Resultados}

\section{QUALIHOSP 2019}
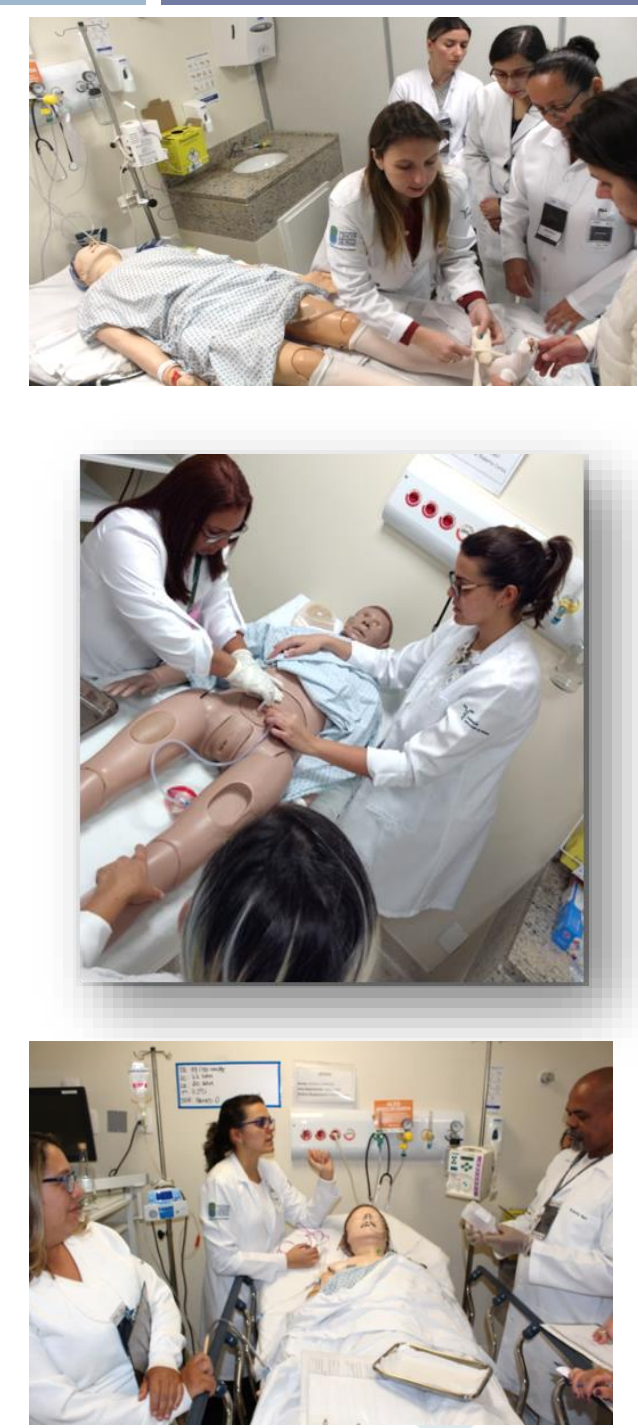

No período de $10 / 2017$ à $03 / 2018$,

70 profissionais de enfermagem foram submetidos à este modelo de treinamento.

\section{Avaliação de Reação:}

Ótimo : $91,8 \%$ dos participantes

Bom: $7,5 \%$ dos participantes

Não avaliaram: $0,7 \%$ dos participantes

Não houve avaliações como "regular" ou

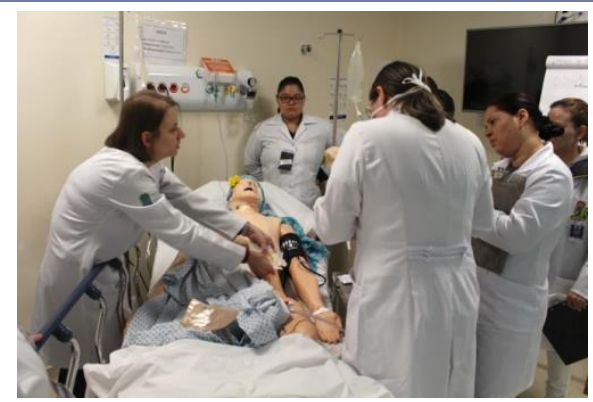

"fraco"
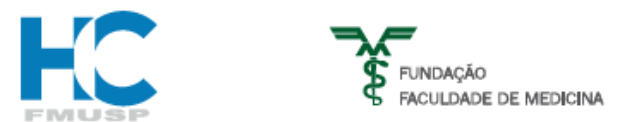

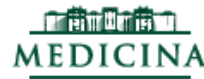
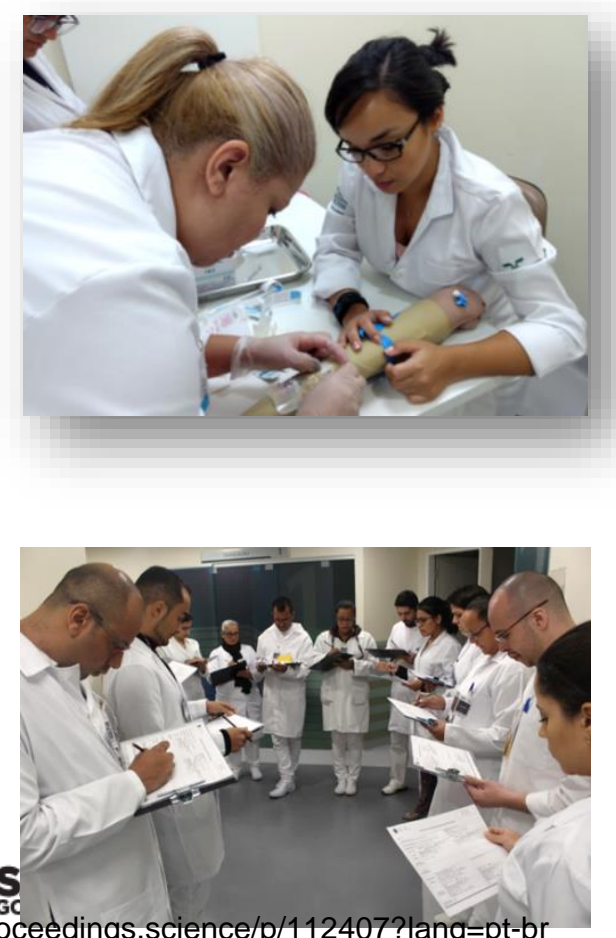


\section{Conclusões}

Consideramos satisfatório o novo modelo de treinamento admissional , com alto nível de satisfação dos profissionais, sendo totalmente factível e viável de ser aplicado na rotina de admissão em ambiente hospitalar. 